\title{
City of London 2007-2010 Green Public e-Procurement Project-Results \& Perspectives
}

\author{
R.N. Lacroix ${ }^{1}$, L. Laios², S. Moschuris ${ }^{3}$ \\ ${ }^{1}$ National School of Public Administration, Athens, Greece \\ ${ }^{2,3}$ University of Piraeus, Greece \\ ${ }^{1}$ richard_lacroix@yahoo.com, ${ }^{2}$ llaios@unipi.gr, ${ }^{3}$ smosx@unipi.gr
}

\begin{abstract}
After years lagging behind Scandinavian and other European Cities, in 2007, the city of London took the courageous initiative to transform itself from a follower to a leader and advocate of Green Public Procurement. In this paper, now that enough data is available, we present how the 2007-2010 Green Public e-procurement project was structured; the goals, accountabilities, results of the procurement portfolio-analysis, the significance of business transformation with e-procurement, the local performance Indicators which were used and the initial spend results of the project. Looking forward, reference is made to planed actions since 2009, regarding the future implementation of European Green Procurement directives and best practices from the supplychain domain. Today, Green Procurement is the central core of the new centrally managed public e-procurement strategy of the city of London which promises to yield significant cost savings and improved efficiencies in the 2010-2013 timeframe.
\end{abstract}

Keywords: city of London, green procurement project, e-procurement, portfolio analysis, performance indicators

\section{Introduction}

In recent years, leading private sector organizations have demonstrated a significant movement towards greening procurement practices (Laios, 2008). Many private firms are working to improve the environmental performance of their operations and products (Laios, 1999) with similar projects and green procurement has been a logical extension of this work. In 2006, the city of London realized the potential and the applicability of best practices of leading private sector organizations to improve their public sector operations. This supply chain approach in the public sector is seen as a means towards improving operations from the environmental perspective to reduce risk (Lacroix, 2008A), (Lacroix, 2006B), total cost of ownership and improve supply chain performance (Lim, 2006).
Despite differences in emphasis, green procurement activities in both the public and private sectors take four main approaches:

- Procuring eco-labeled products or services

- In-house product/service evaluations

- Third-party product/service evaluations

- Supply chain initiatives

In the following sections of this paper, now that enough data is available, we present in some detail the city of London 2007-2010 Green Public eprocurement project. This paper is structured into nine sections:

1) Introduction - this section,

2) The project's definitions, context and goals,

3) Green Procurement the corner stone of the new centrally managed public e-procurement strategy

*Corresponding Author 
4) The project spend categories,

5) The project organization,

6) The project control mechanisms through local performance indicators,

7) The project e-procurement implementation,

8) The new pyramid-shaped procurement development program,

9) The conclusion of the project with perspectives for the future.

\section{The project's definitions, context and goals}

\subsection{Definitions}

"Procurement" is the process of acquiring goods, works and services, covering both acquisitions from third parties and from in house providers. . For the City of London, the process spans the whole cycle from identification of need through to the end of the useful life of an asset. It involves option appraisal and the critical "make or buy" decision which may result in the provision of services in house in appropriate circumstances." (National Procurement Strategy for Local Government, 2003).

"e-procurement" Electronic procurement (EProcurement) is the use of information and communications technology (ICT) to facilitate procurement processes. For the City of London, eprocurement embraces the automation of a wide range of procure to pay (P2P) applications, (Municipality of London 2010) including requisitioning, ordering, bill payment, competitive tendering, inventory management, contract management, on-line auctioning, tender analysis and approved list systems.

"Green Procurement" is the purchase of environmentally preferable products and services in accordance with one or more of the established "green" procurement preference programs. For the City of London, Green procurement is the purchasing of products or services which have a lower impact on the environment over their whole life cycle than the standard equivalent. It involves the integration of environmental issues into purchasing decisions based on price, performance and quality. In most organizations, greening the supply chain requires a comprehensive understanding of one's supplier relationships: which suppliers most affect environmental (Lacroix, 2007), (Lacroix, 2006B), health, and safety costs, risks, and reputation; which represent the greatest leverage points for efficiency and cost improvements; how to communicate effectively with suppliers on EH\&S issues; and what are meaningful and verifiable means of tracking and measuring supplier environmental performance.

\subsection{Project Context}

Following the publication of «Green Public Procurement in Europe». A study undertaken by the Commission in 2005 on the 'State of Play of Green Public Procurement in the European Union' which revealed the wide variation in achievement in this area within Europe. Denmark showed an impressive amount of commitment to green public procurement with $40 \%$ of administrations that include environmental criteria for more than $50 \%$ of their purchases. Similarly in Sweden $50 \%$ of administrations include environmental criteria for more than $50 \%$ of their purchases. Germany rated third with $30 \%$ and the UK at 23\% still beat the average of $19 \%$. This report highlighted the fact that public organizations in the European Union like the city of London could learn from the example of Denmark and Sweden.

This lead in 2006 to the decision that an eprocurement project founded on the principles of Green procurement was needed. The project started in 2007, the initial timeframe was set to last from 20072010, and set to end in mid-2010.

The initial project coming to it's end this year, having exceeded the intended initial goals, and data having confirmed that the project has brought positive results, it is expected that this project will be followed by a newer project at the end of 2010 for the timeframe 2010-2013 whose aim will be the systematic adaptation and implementation of European Green Procurement directives together with new developments from best practices from the supply-chain domain. Besides educational needs. The new project will look at how the "green" procurement activities require further business process reengineering so that they can be better integrated into future environmental and quality management systems.

\subsection{Project Goal}

There is wide recognition within the City of London Corporation and throughout that effective procurement techniques need to be applied across 
all categories of non-pay expenditure, and in particular in areas of high value and risk, such as construction and social care as well as reducing the process costs of high volume low value purchases. In implementing this project, the City of London Corporation acted in accordance with the following goal and objectives:

Goal: To support the delivery of innovative, costeffective and high quality services in fulfillment of the City of London Corporation's aims and priorities within its Corporate Plan 2007-10 and The City Together Strategy (the sustainable community strategy for the Square Mile and City fringes).

Objectives:

1. Ensure that procurement practice contributes to the effective use of resources as set out in the Guidance on National Indicator 179 (NI179) on Value for Money Gains and Comprehensive Area Assessment

2. Ensure that procurement delivers year on year efficiencies and savings

3. Ensure that the quality is measured by seeking feedback from customers

4. Secure commitment to effective, consistent and coordinated procurement from members and officers to achieve the delivery of high quality, innovative and cost-effective services

5. Encourage long-term thinking and commitment to a strategic approach to procurement issues

6. Ensure that whole life costing methods are used to assess and evaluate costs and benefits over the entire life of assets and services

7. Establish a mechanism to link procurement action plans to this strategy and promote the continuous improvement of procurement activity across the City of London Corporation

8. Provide greater visibility and understanding of the role of the procurement function

9. Develop skills and provide support for staff involved in procurement

10. Promote and deliver sustainability, local economic development, equality and diversity objectives throughout our procurement activities

11. Continue to use and further develop procurement collaboration with other public bodies and partnering arrangements with suppliers
12. Recognize the contribution of procurement to achieving our community, corporate, departmental and service objectives

13. Raise awareness of the complex regulatory framework in which procurement operates \& that it is potentially high risk; with financial, legal, environmental, health \& safety \& reputation impacts.

\section{Green Procurement the corner stone of the new centrally managed public e-procurement strategy}

Green procurement embraces environmental and social objectives and can deliver long term economic benefits. It has helped the City achieve the vision outlined in the city of London's "Sustainable Community Strategy":

Through green procurement, the City of London Corporation not only was able to meet relevant statutory requirements but was also able to adopt whole life costing principles into its procurement activities particularly in relation to major projects and corporate contracts. This has meant assessing and evaluating all costs and benefits over the entire physical life and disposal of goods and services. The City of London has also developed a Sustainability Framework which was used at the development and implementation stages of significant schemes and proposals many of which include major procurement projects. For ease of reference the City's Green Procurement Strategy is divided into environmental and social sections.

\subsection{Green Procurement - Environment}

The Sustainable Community Strategy details the following Green-related matters, which are considered in procurement decisions:

1) Greenhouse Gas emissions / energy consumption

2) Water consumption

3) Waste and recycling

4) Transport

5) Biodiversity, nature conservation and greening

6) Noise, land and water pollution

7) Air quality

8) Responsible consumption 
The City of London Corporation recognized that it also has impacts on distant communities through its supply chains. It has therefore passed a Fair trade resolution committing it to actively support and promote the concept of fair trade and to purchase Fair trade and fairly traded products whenever possible.

The City of London Corporation therefore committed and has taken the following actions:

1) Where possible, reduce procurement of new products by ensuring the effective maintenance of goods and assets, repairing or reusing existing products and identifying and addressing wasteful procurement practices.

2) Establish detailed policies and guidelines for products and services with a significant environmental impact such as timber, construction materials, energy, fuel, food, vehicles and equipment, stationery, clothing and cleaning products.

3) Support staff in the delivery of this policy by raising awareness of the environmental issues affecting procurement through provision of appropriate training, information and guidance.

4) Continually review its direct purchases and contract specifications with the intention of reducing the environmental impact of its goods, works and service purchases.

5) Include environmental considerations on its assessment of suppliers and their products and engage with suppliers to improve their environmental performance and the environmental performance of the goods and services they provide.

6) Ensure environmental considerations are included in all contract documentation.

7) Specify environmentally and socially acceptable products, services and ways of working in contract conditions and specifications, where possible. In particular, specify products which are made from recycled materials; materials that can be recycled and re-used; can be operated in an energy efficient manner that cause minimal damage to the environment in their production, distribution, use and disposal, so long as the requirements of value for money and quality are met.
8) Provide active support for the Mayor of London's Green Procurement Code and communicate this to staff.

9) Wherever possible ensure that the final disposal of redundant or obsolete assets is in accordance with the waste hierarchy and relevant legislation, and after all reasonable opportunities for re-use have been explored.

10) Avoid the use by the City, or its appointed agents, of certain environmentally damaging products where the use of more suitable products, or production methods, is possible. These products include:

- Ozone depleting chemicals

- Tropical hardwood which is not independently certified as coming from sustainable forests

- Peat for soil amelioration

- Adopt mechanisms and indicators for improving, monitoring and reviewing the environmental performance related to its procurement function.

\subsection{Green Procurement - Social}

\section{Equality and Procurement}

Equality is one of the City of London's core values and it recognized the important role that procurement can play in promoting equalities and fighting discrimination. The city has done this in accordance with their existing "Equalities in Service Delivery Policy" and in ways that are consistent with value for money policy, the UK procurement regulations and EU Procurement Directives.

The city has been meeting their obligations under The Disability Discrimination (Amendment) Act 2005 and the Disability Equality Duty; The Sex Discrimination Act 1975 (as Amended) and the Equal Pay Act 1970 (as Amended) and the Gender Equality Duty; The Race Relations (Amendment) Act 2000 and the Race Equality Duty, Employment Equality (Sexual Orientation) Regulations 2003 and Employment Equality (Religion or Belief) Regulations 2003.

Since 2007, the city has been considering equality issues before major procurement projects starts by conducting equalities impact assessments and ensuring the requirements of diverse customers were addressed, as well as relevant opportunities pertaining to suppliers as below. 
- In specifications, ensuring relevant equality requirements were addressed e.g. access to buildings for disabled people.

- At selection stage, asking suppliers for evidence of professional or technical ability e.g. for services to ethnic minority communities, cultural awareness and language skills.

- Contract conditions were used to further equality outcomes where they related to the performance of the contract and were indicated in the contract notice or specification e.g. the obligation to recruit a number of disabled people to be employed for the duration of the contract.

- Considered whether it was appropriate on the basis of their user requirement and specification to reserve a contract for organizations providing supported employment opportunities for disabled people.

- Reduced barriers to, and improving the opportunities for, diverse suppliers that wished to compete for Government contracts, particularly by reducing the bureaucracy involved in competing for a delivering such contracts.

- Where appropriate, worked with suppliers on a voluntary basis to promote the importance of equality to their suppliers and supply chain, for example including suppliers' workforce on internal equality and diversity training courses.

- Strived to ensure that procurement assisted the City in attaining the Equalities and Human Rights Commission Level 4 standard on equalities.

\section{Local Procurement}

A key part of the City's drive for Green procurement has been to take positive steps to use procurement as a way of benefiting disadvantaged local communities. They have therefore developed a Local Procurement Strategy for businesses in the City and in postcodes adjacent to the City in the following boroughs; Tower Hamlets, Southwark, Hackney, Lambeth, Islington, Camden and Newham.

Small contracts are covered by the Local Procurement Directive: "It is required that when seeking quotations for all contracts of a value in excess of $£ 500$ and up to the EU threshold (currently $£ 139,893$ ) for supplies and services and to $£ 400,000$ for works, the officer seeking quotations must ensure that at least one firm located in the local procurement target boroughs is invited to quote, where possible."

Larger contracts in the City are subject to Community Benefits Scheme where appropriate which identifies suitable contracts and encourages suppliers to enter into voluntary agreements to employ, subcontract and procure in the LPP target areas to the value of $10 \%$ to $20 \%$ of the contract value. This allows local (Small-Medium-Enterprises) SME's to participate in larger projects and programs they might not have been able to compete for and provides an incentive for suppliers to employ local residents and undertake their own local procurement programs.

A permanent full time officer has been deployed in the SPU to promote the Local Procurement Policy internally. This project was initially time limited to 4 years (starting in 2007) but is now (2010) fully embedded in the City's procurement strategy and procedures. At the same time, The city's Economic Development Office promotes the City's good practice on local procurement to the commercial square mile commercial sector via the Partnerships Team.

\section{Small and medium enterprises}

The City of London recognized the importance of small and medium enterprises to its own supplier base and the wider British economy and the difficulties many face during the current economic downturn. Measures taken by the City to support the SME sector include signing an SME concordat to set out clear fair and consistent rules of engagement, reducing payment terms to 10 days together with the local procurement project mentioned above. In addition, the City is committed to implementing as many as possible of the recommendations of the recent Glover Report (Accelerating the SME economic engine November 2008) as of 2010.

\section{The third sector}

A key part of the City's approach to Green procurement has been to engage and work in partnership with the third sector, made up of 
charities and voluntary and community organizations. The City's Local Strategic Partnership has produced a Compact, a voluntary agreement between the public sector and the third sector, which sets out how they will work together in partnership for mutual benefit and for wider community gain. The Compact, which also includes a Commissioning Code of Practice, aims to "ensure a cohesive and vibrant relationship between the public and third sectors in the City of London - a relationship which promotes the city's role as a world class city and to maximize high quality, accessible and responsive services for workers, residential and business communities."

\section{Summary of Achievements}

In the last 4 years (2007-2010) the city has had a good track record of incorporating environmental and social sustainability into their procurement procedures. This said, they still need to further embed good practice by producing better practical sustainable procurement guidance for officers and systematically recording progress and continue the measures taken in that direction in 2009/2010. The city has produced clear guidance on incorporating sustainable principles into procurement decision making such as the use of sustainability and equalities impact assessments. The city has also draw up an action plan for ensuring that their equalities procurement procedures meet the requirements of Equalities Level 4 standards and incorporated this plan into the strategic review of procurement. The city has facilitated further courses on Green procurement to communicate the message; it has also started Implementing as many as possible of the Glover Reports recommendations on supporting SME's as of 2010.

\section{Project spend categories}

The City of London Corporation spent $£ 246 \mathrm{~m}$ on external goods, services and works in financial year $2008-2009$. Some of the main features of this spend are set out in the following diagram 1.

\section{The city's Portfolio Analysis}

The following two diagrams break down the City's expenditure into four broad categories based
Diagram 1. City of London Expenditure Analysis

$\begin{array}{ll}\text { Overall Spend } & £ 246 \mathrm{~m} \\ \text { Suppliers } & 13,880 \\ \text { Number of Invoices } & 128,145 \\ \text { Percentage of Invoices less than } £ 100 & 38.5 \% \\ \text { Percentage of Invoices less than } £ 500 & 71.0 \% \\ \text { Percentage of Suppliers generating top 20\% tranche of spend } & 0.02 \% \text { (3 suppliers) this is } \\ \text { totally skewed by some large one off construction contracts } & 0.29 \% \text { (40 suppliers) } \\ \text { Percentage of Suppliers generating } 50 \% \text { of spend } & 3.24 \% \text { (450 suppliers) } \\ \text { Percentage of Suppliers generating } 80 \% \text { of spend } & £ 1,435 \\ \text { Average invoice value } & 5.4 \% \\ \text { Percentage of spend managed through corporate contracts } & \\ \text { Percentage of spend managed through collaborative contracts } & 5.38 \% \\ \text { via other authorities } & 96.76 \%(13,430) \\ \text { Percentage of Suppliers generating bottom 20\% of spend } \\ \text { suppliers) }\end{array}$

on a risk/value matrix. The relative combination of risk and value can help to determine the most appropriate procurement strategy and organizational structure. Diagram 2 sets out the

\section{Diagram 2. Procurement Portfolio Analysis}

\begin{tabular}{|c|c|c|c|}
\hline \multirow{2}{*}{\multicolumn{2}{|c|}{$\begin{array}{l}\text { Bottleneck High Risk/Low Value } \\
\text { Ensure supplies }\end{array}$}} & \multicolumn{2}{|c|}{ Strategic High Risk/High Value } \\
\hline & & \multicolumn{2}{|c|}{ Contract management } \\
\hline \multicolumn{2}{|c|}{$\begin{array}{l}\text { Specialist Equipment, Raw } \\
\text { Materials, Training, Medical, } \\
\text { Research \& Testing, vital spares }\end{array}$} & \multicolumn{2}{|c|}{$\begin{array}{l}\text { Social Care, Property Construction \& } \\
\text { Maintenance, Waste Management, } \\
\text { Housing, Related Support, ICT Capital } \\
\text { Projects, Outsourcing, }\end{array}$} \\
\hline$£ \mathrm{M}$ & 26.5 & $£ \mathrm{M}$ & 125.4 \\
\hline Percentage & $11 \%$ & Percentage & $51 \%$ \\
\hline \multicolumn{2}{|c|}{ Routine; Low Risk/Low Value } & \multicolumn{2}{|c|}{ Leverage Low Risk/High Value } \\
\hline \multicolumn{2}{|c|}{ Minimum attention } & \multicolumn{2}{|c|}{ Drive for savings } \\
\hline \multirow{8}{*}{\multicolumn{2}{|c|}{$\begin{array}{l}\text { Stationery and Office Supplies } \\
\text { Curriculum Supplies } \\
\text { Furniture and Fittings } \\
\text { Cleaning, Janitorial and Hardware } \\
\text { Advertising } \\
\text { Medical Equipment and Living Aids } \\
\text { Plant, Tools and Machinery } \\
\text { Health \& Safety, Security, Storage \& } \\
\text { Removals }\end{array}$}} & \multirow{8}{*}{\multicolumn{2}{|c|}{$\begin{array}{l}\text { Utilities and Fuels } \\
\text { IT Equipment and Services } \\
\text { Telecommunications } \\
\text { Agency Staff } \\
\text { Cleaning, Disposal and Recycling } \\
\text { Printed and Pre-Recorded Media } \\
\text { Food and Drink } \\
\text { Catering and Hire of Facilities } \\
\text { Design, Print \& Promotional Services } \\
\text { Vehicle Supplies \& Services Financial } \\
\text { \& Legal Services, Landscaping \& } \\
\text { Grounds Maintenance }\end{array}$}} \\
\hline & & & \\
\hline & & & \\
\hline & & & \\
\hline & & & \\
\hline & & & \\
\hline & & & \\
\hline & & & \\
\hline$£ \mathrm{M}$ & 24.5 & $£ M$ & 69.6 \\
\hline Percentage & $10 \%$ & \begin{tabular}{|l|} 
Percentage \\
\end{tabular} & $28 \%$ \\
\hline
\end{tabular}

types of goods and services in each category along with a value and percentage of overall spend.

Diagram 3 sets out some of the most commonly used tactics and strategies to deal with each spend category.

\section{Summary and Actions}

- $3 \%$ or 450 of the City's suppliers account for $80 \%$ of expenditure.

- The converse is that $97 \%$ of the City's suppliers account for the bottom $20 \%$ of expenditure 
Diagram 3. How the Procurement Portfolio is managed

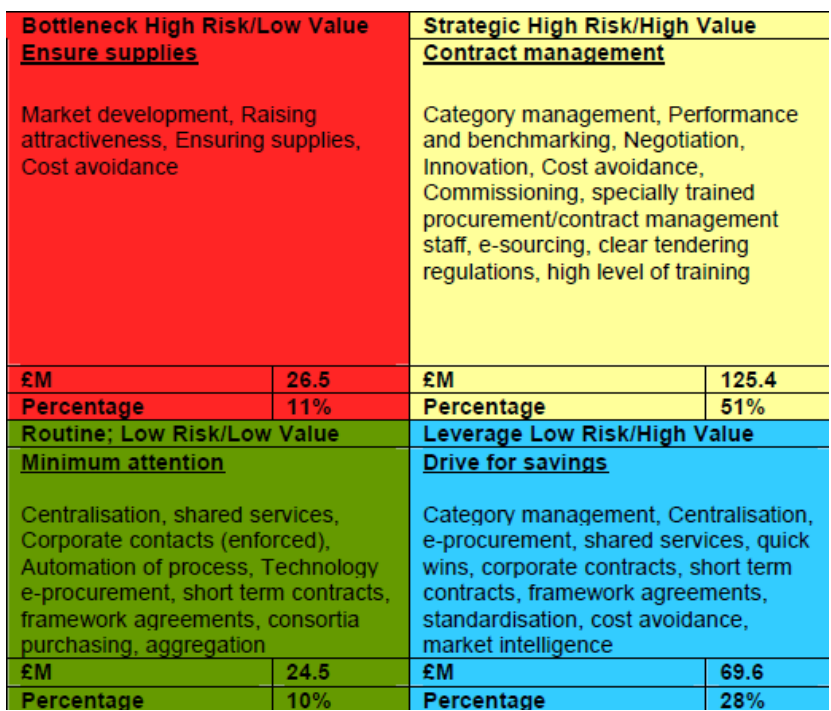

- The highly devolved nature of the City's procurement structure in which $90 \%$ of expenditure is devolved to departments and only $10 \%$ devoted to corporate contracts, may account for the large number of low value suppliers and invoices

- Further analysis needs to be undertaken in conjunction with an overall review of the City's procurement structure to determine whether there are more efficient ways of managing the City's low value expenditure.

- The portfolio analysis broadly follows the findings of the expenditure analysis; approximately $20 \%$ of expenditure is accounted for by low value items and $80 \%$ by high value items.

- Going forward, our strategy is to reach the point of no classification limitations based on the CIPFA mixture of objective and subjective codes by providing additional classification based on the Pro Class system.

- A further analysis needs to be undertaken to determine the division of the City's procurement capacity in order to ensure that the resources are correctly aligned to expenditure. To be undertaken with a detailed review of procurement commencing in mid 2010

\section{Project organization}

Existing Capacity: The City of London has a largely devolved procurement structure; more than 1,000 officers out of an establishment of approximately 3,500 are able to place orders via the City's electronic ordering system. Many more are involved in the bill payment process and in the procurement process as project, budget and contract managers. 8 officers are fully or partially qualified to Chartered Institute of Purchasing diploma standard; 4 in the Strategic Procurement Unit, 1 in the Barbican Centre, 1 in the City of London Police and 2 in Community and Children's Services.

Executive responsibility has been facilitated by the appointment of a Procurement Board to oversee the implementation of the City of London procurement strategy and ensure that leading edge procurement systems and practices are developed, and that staff are appropriately trained in order to deliver maximum long term efficiencies and strategic support to the Community Strategy and the Corporate Plan.

Service and Budget Managers are responsible for managing the delivery of the City of London's objectives through their own service plans. They have devolved responsibility for service planning, budget management and procurement activities. Service and budget managers are therefore key to ensuring the effective adoption and delivery of this procurement strategy.

Members have a key role to play in aligning procurement decisions with the City of London Corporation's corporate objectives and in monitoring procurement performance. Our Finance Committee has the ultimate responsibility for overseeing the procurement function.

Central coordination: The Exchequer and Business Support Director of the Chamberlain's department leads strategic procurement and also oversees the Strategic Procurement Unit (SPU) which undertakes the role of a corporate procurement team and is responsible for:

- putting in place corporate arrangements for the purchase of common use goods and services (indirect supplies) on behalf of all departments

- providing a procurement support and review service to departments and individual contracts 
- developing procurement strategy, policies and procedures

- co-ordination and consistency within the procurement process

- delivering appropriate e-procurement solutions

- fostering collaboration with other public bodies

- supporting the activities and providing a link to the procurement arm of Capital Ambition the Regional Improvement and Efficiency Partnership (RIEP) for London

The Procurement Practitioners Forum represents all departments and is responsible for consulting on and implementing corporate procurement initiatives and performance at operational managerial level. In particular to:

- develop procurement practice across all departments

- report and improve on performance

- build more corporate procurement arrangements

- support knowledge and information sharing.

- performance management for procurement within the current structure is centrally coordinated by the Exchequer and Business Support Director of the Chamberlain's department supported by and through a combination of the following measures.

- corporate governance by the Procurement Board

- monitoring progress on the implementation of the procurement strategy via a linked annual procurement action plan with milestones and regular updates on progress to the Procurement Board

- annual performance reviews for procurement staff

- efficiency targets for corporate procurement initiatives

- review of procurement operations and procedures by the Procurement Practitioners Forum

- collating procurement efficiency gains for the Procurement Board and NI 179 for the Comprehensive Area Assessment

- building procurement capacity by facilitating a learning and development program for City of London staff

- making the fullest use of the City's information systems to provide procurement intelligence and expenditure analysis

- liaising with other public sector procurement organizations to share intelligence for market research, benchmarking and collaborative procurement opportunities

- ensuring that all major contracts have appropriate, project, contract and performance management arrangements

- monitoring and auditing compliance with external regulations and the City's standing orders, policies and guidance for procurement

- ensuring that appropriate procedures are in place to proactively manage budgetary, financial, supplier performance, legal, and health and safety risks

\section{Project control mechanisms - local performance indicators}

Local performance indicators in order to further underpin the performance management arrangements the City of London has selected the following local performance indicators for scrutiny and action by their Procurement Board. These are set to be amended or supplemented at the end of 2010 with new indicators as the City's procurement structure develops. Diagram 4 lists the seven Local performance indicators used by the city.

Diagram 4. Local Performance Indicators

\begin{tabular}{|l|l|}
\hline Local Performance Indicator 1 & $\begin{array}{l}\text { \% of corporate expenditure aggregated through } \\
\text { corporate agreements and corporate contracts }\end{array}$ \\
\hline Local Performance Indicator $\mathbf{2}$ & $\begin{array}{l}\text { \% of corporate expenditure aggregated through } \\
\text { collaboration with other public sector } \\
\text { organisations. }\end{array}$ \\
\hline Local Performance Indicator 3 & $\begin{array}{l}\text { Average invoice value, corporate spend } \\
\text { aggregated by total of invoices }\end{array}$ \\
\hline Local Performance Indicator 4 & $\begin{array}{l}\text { Value of cashable efficiencies achieved in a } \\
\text { financial year for corporate procurement initiatives }\end{array}$ \\
\hline Local Performance Indicator 5 & $\begin{array}{l}\text { Local Supplier spend in Local Procurement Project } \\
\text { Target areas }\end{array}$ \\
\hline Local Performance Indicator 6 & $\begin{array}{l}\text { Community Benefit Clause expenditure in all City } \\
\text { of London contracts }\end{array}$ \\
\hline Local Performance Indicator 7 & $\begin{array}{l}\text { Percentage of invoices paid within 30 days and 10 } \\
\text { days }\end{array}$ \\
\hline
\end{tabular}

\section{Project e-procurement implementation}

For the City of London, e-procurement embraces the automation of a wide range of procure to pay (P2P) applications, including requisitioning, ordering, bill payment, competitive tendering, inventory management, contract management, on-line auctioning, tender analysis and approved list systems. Overall responsibility for the eprocurement strategy rests with the Procurement 
Board. Responsibility for the development and implementation of the corporate e-procurement strategy resides with the Chamberlain's department Strategic Procurement Unit in consultation with departments via the Procurement Practitioners Forum.

Project plan Major Activities: The following project plan highlights the main tasks which were required to implement the elements of eprocurement in the various stages of the procurement cycle which the City of London has deemed would provide the greatest benefits and were appropriate to its needs:

Advertising of opportunities: The City of London advertizes all supplies and services contracts above $£ 50,000$ on their internet site to the business community, publishes information on how to do business with the City and provides access to pre-tender questionnaires. Contracts for Works, Services and Goods above the current EU thresholds are advertized in the Official Journal of the European Union.

Sourcing and tendering: The benefits of electronic sourcing (e-tendering) have been recognized by the City and following a selection process, they have been implementing a corporate system supplied by a company called Due North in 2009. This system has started to automate the whole tendering and quotation system in the City of London. It has created a live corporate contracts register and provides links to the City's internet site and the Official Journal of the European Union for higher value contracts. This system will also place the City in a better position to monitor supplier performance and coordinate and measure procurement efficiencies.

E-marketplaces: They are currently hosting 2 electronic catalogues on their financial (CBIS) system and believe it is appropriate to continue to do so pending any future integration with an eMarketplace. The strategy thus far has been to work with key corporate suppliers on developing electronic catalogue uploads or 'punch-out' to their own internet catalogues. In 2010 they are currently evaluating some of the major public sector marketplace providers and the associated costs. It is not clear at this stage whether the City of London would derive major commercial benefits at the prices and functionality being quoted. However they will review this decision in the medium to longer term as the market develops.

Ordering: The majority of the City's electronic orders are raised via the City of London's Oracle system (CBIS), though a large proportion of property related orders are raised via the City Surveyor's Manhattan system. Purchase orders are sent to suppliers by auto fax, electronically (XML format) or on paper.

Goods receipting and delivery notes All CBIS purchase orders require electronic goods receipting and this process is a pre-requisite for enabling more automated invoice processing and facilitates the preparation of the City of London's year end accounts.

Invoice processing: There are a number of different approaches which were adopted for invoice processing. These are:

- Consolidated invoicing (one invoice covers more than one purchase order)

- Electronic processing of invoices against individual purchase orders

- Self-billing (known as 'evaluated goods receipt' in), where invoices are not submitted, but payment is made by processing the goods receipt transaction.

The electronic receipt of invoices against individual purchase orders will reduce the volume of manual keying locally and will facilitate automatic payment where the invoice matches the purchase order and goods receipt.

Payment: For many years, and in line with BVPI 8 , it has been City of London policy to pay all invoices within 30 days. For the 2007/2008 financial year they paid $96.84 \%$ of undisputed invoices within 30 days, and in 2008/09 year to date (April - Dec) they have so far achieved $97.82 \%$. During the current economic crisis, the City of London has acted to support the Government initiative to pay Small and Medium Enterprises (SMEs) within 10 days, and have amended the payment terms on CBIS system for any suppliers that they understand to be SMEs to 10 days. It is too early in 2010 to measure the impact this has had on their average timescale for payment.

Purchasing cards: The use of purchasing cards reduces transaction costs particularly for low value or ad-hoc purchases. In the past year (2009) they have expanded the use of the Government 
Procurement Card (GPC) and will continue to do so.

E-auctions: The City of London has participated in the use of auctions, for computer hardware where significant cashable efficiencies were made. They will continue to utilize e-auctions when suitable commercial opportunities are identified.

Disposals: The City of London uses an online disposal system to advertise and allow departments and external organizations to transfer or bid for redundant assets.

Summary and actions

1. The City has made steady progress with eenabling much of our procure to pay processes

2. The introduction of new e-procurement applications has brought operational and in some cases cashable efficiencies.

3. The implementation of the Due North esourcing system in 2009 will bring significant operational benefits to the tendering and contract management processes of the City London. It will also replace several pre-existing stand alone systems such as BIP Tender Notices, Local Supplier Database and Alito.

4. Further substantial savings will be realized when development of e-procurement is aligned to a review of the City's procurement structure.

Diagram 5. The City's New Centrally Managed Procurement Structure

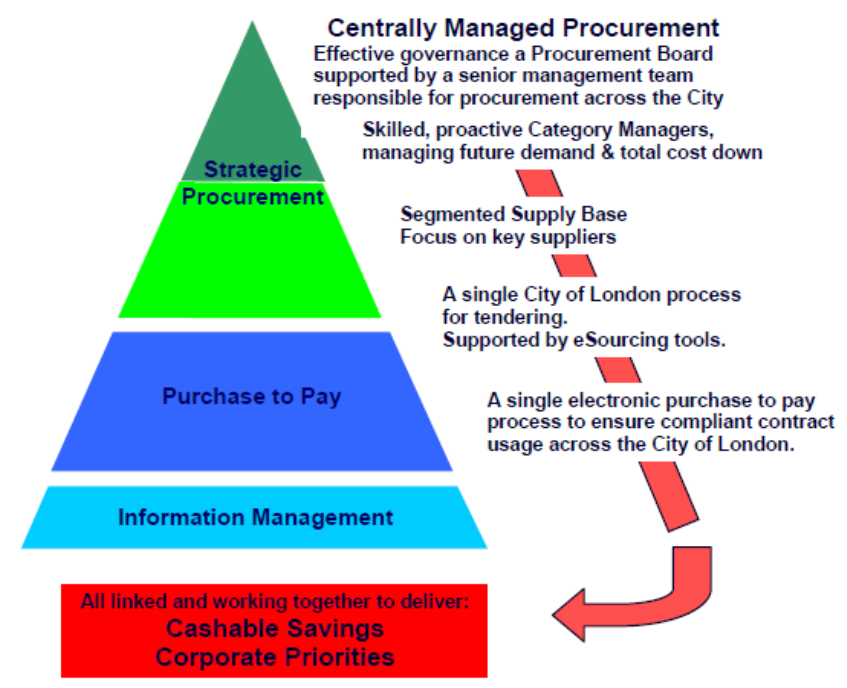

5. The impact of the reduced 10 day payment terms for SME's will be reviewed in 2009

8. The new pyramid-shaped procurement development program

As part of its ongoing procurement development program the City of London has committed to reviewing its current devolved procurement structure during 2010 and moving to a more integrated structure during 2010/2013.

Diagram 5 sets out the type of organizational structure that the City will strive to move towards. This model recognizes that the various procurement processes would benefit from being viewed and managed as a whole rather than separately.

Summary and actions

1. The City is committed to a comprehensive review of its procurement structure and processes

2. Embedding category management is fundamental to any restructuring of the procurement function

3. The City will draw upon external examples of best practice in determining its future structure

4. The City will seek to leverage external partnerships to facilitate change

\section{Conclusion}

As this paper illustrates, the city of London is realizing the direct benefits of green public procurement practices:

1) Cost avoidance-lower waste management fees, lower hazardous material management fees, less time and costs for reporting;

2) Savings from conserving energy, water, fuel and other resources (Khiewnavawongsa, 2008),(Lacroix, 2008B),(Lacroix, 2006B),(Lacroix, 2005);

3) Easier compliance with environmental regulations;

4) Reduced risk of accidents, reduced liability and lower health and safety costs; (Hill, 1993), (Isaak, 1998);

5) Support of environmental/sustainability strategy and vision (Lacroix, 2007),(Lacroix, 2006A);

6) Improved image, brand and goodwill; 
7) Improved employee and community health through cleaner air and water, less demand for landfill and less demand for resources (Lacroix, 2008B),(Lacroix, 2006A);

8) Improved efficiency benefits from eprocurement in terms of speed of delivery, tracking, accountability, and volume discounts from fewer strategic suppliers.

9) In the last couple of years, the city is also reaping more qualitative benefits such as improved image and achieving policy/ program objectives.

All this effort finds the city better equipped to face the challenges of tomorrow. In 2010, the city of London has metrics in place to: measure direct cost savings; estimate environmental benefits; report money spent; estimate hidden costs and potential savings. It is also doing all the right things for a systematic adaptation and implementation of European Green Procurement directives together with new developments from best practices from the supply-chain domain. Today, Green Procurement is the central core of the new centrally managed public e-procurement strategy of the city of London which promises to yield significant cost savings and improved efficiencies in the 2010-2013 timeframe. As of 2011 the city plans to continue fostering green procurement. The major activities that have been identified include: 1) Continuing education and awareness on the business case, and best practices for green procurement, including networking between practitioners, and other public sector organizations. 2) Promoting, adopting and expanding procurement criteria among government procurement practitioners. 3) Explore and focus on an expansion and evolution of the existing Green e-procurement project for 2013 and beyond for education with a discussion on how the "green" procurement activities require further business process reengineering so that they can be better integrated into future environmental and quality management systems. Does that mean that the work is essentially finished and that the city can rest on its laurels? No, quite the opposite, this is only the beginning of a long term commitment to the environment. What most people need to comprehend now is that even if from 2010 and beyond, the city manages to continue progress at the same rhythm, once these waste elimination and cost cutting initiatives will have reached maturity, the city will have to make the tough decisions regarding investment into business reengineering if it is to reap the benefits of the integrated supply chain.

\section{References}

Green Public Procurement in Europe (2005), European Commission at http://ec.europa.eu/environment/gpp/ pdf/report facts.pdf

Hill, T. (1993), Manufacturing Strategy, McGraw-Hill.

Isaak R, (1998), Green Logic: Ecopreneurship, Theory and Ethics, Sheffield: Greenleaf

Khiewnavawongsa, S. \& Schmidt E. K., (2008), Green Power to the Supply Chain, Purdue University, Indiana.

Lacroix, R., (2008a), Green Procurement and Entrepreneurship, Harokopeio University, Scientific conference "Innovation-Entrepreneurship", 15 May 2008, 23 pages, (Proceedings on CD), Athens, Greece.

Lacroix, R., (2008b), Energy and Eco-Development in France, (for NTUA), published on www.brainet.gr - January 2008.

Lacroix, R., Stamatiou, E., (2007), Green Architecture and Sustainable Development: Applications \& Perspectives, 3rd IASME / WSEAS Int.Conf. on Energy, Environment, Ecosystems and Sustainable Development (EEESD'07), Agios Nikolaos, Crete Island, Greece, July 24-26, 2007, ISSN 1790-5095, ISBN 978-960-8457-88-1, pp. 602-605.

Lacroix, R., Stamatiou, E., (2006a), The French Experience with Habitat, Sustainability and Quality of Life, WSEAS International Conf., Vouliagmeni, Greece, 11-13 July 2006, Journal WSEAS Transactions on Energy, Environment, Ecosystems and Sustainable Development, Issue 5, Vol. 2, May 2006 (ISSN 1790-5079) pp 584-590.

Lacroix, R., Stamatiou, E., (2006b), Green Roofs - A 21st Century Solution to the Urban Challenges of Green Space, Air Pollution, Flooding \& Energy Conservation, WSEAS International Conference Vouliagmeni, Greece, 11-13 July 2006, Journal WSEAS Transactions on Energy, Environment, Ecosystems and Sustainable Development 2 (2), pp. 909-918.

Lacroix, R., Stamatiou, E., (2005), Coastal Land Acquisition and Management towards the protection and restoration of natural spaces and landscapes. The 30 Years experience of the CELRL in France, Ôñßôi

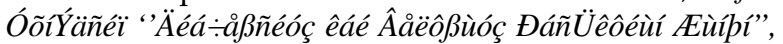
ÃñáóôPñéi Ëéìåiéêbí , ñãùi ÅİĐ, 22-25 İïåiẫñß̈̃̃ 2005, ó.ó. 517-528

Laios, L., and Moschuris, S. (1999), An Empirical Investigation of Outsourcing Decisions. The Journal of Supply Chain Management 35 (1), pp. 33-41. 
Laios, L., (2008), The Perceived Impact of E-Procurement in EU Enterprises. International Journal of Value Chain Management 2 (2), pp. 168-187.

Lim Roland Y.G., Baines Tim, Tjahjono Benny, Chandraprakaikul Watcharavee, (2006), Integrated Strategic Supply Chain Positioning for SMEs: An Empirical Study, The International Journal of Logistics Management 17 (2), pp. 260-276.
Municipality of London Web site (2010),http:// www.cityoflondon.gov.uk/Corporation

UK National procurement strategy for local government (2003), www.odpm.gov.uk.

Richard-Nicolas LACROIX teaches quality management at the graduate school of sustainable development at Harokopeio University, project management at the National School of Public Administration and at the Hellenic Management Association, Computer Science courses at the Athens Technological University, at SELETE Pedagogical University in Athens, Greece. Richard-Nicolas LACROIX is the author of a book in Greek on Green Procurement (2010). He received his MBA from the National Technological University in Athens, Greece, he is a graduate of the school of Computer Science and Engineering of George Mason University, USA. He is also a PHD candidate in the Department of Industrial Management and Technology, at the University of Piraeus, Greece. His teaching, research, and consulting interests include green procurement, computer science, and quality management. He has extensive project management and consulting experience with boards of multi-national companies in the US and in Europe. His research work has been published in several journals and conference proceedings. He is an honorary member of the Greek Regional Development Association at Panteion University, a member of the Greek Public Administration Society, and a member of John Butcher's RUNGE-KUTTA club at the department of Mathematics of the University of New-Zealand.

Lambros G. Laios is Vice Rector and Professor of Ergonomics and Purchasing Management at the Department of Industrial Management and Technology, University of Piraeus, Greece. He received his PhD degree from the Loughborough University of Technology, UK. His teaching, research, and consulting interests include purchasing, logistics, materials management and ergonomics. He has extensive project management and research experience in more than 50 major E.U. and National programs in the fields of Supply Management and Human Factors. His research work has been published in a large number of journals including Omega, European Journal of Marketing, Production and Inventory Management Journal, Journal of Business Research, and Journal of Supply Chain Management. He is the President of the Hellenic Purchasing Institute (member of the IFPSM) and a member of the Human Factors and Ergonomics Society.

Socrates J. Moschuris is an Assistant Professor of Logistics and Supply Management at the Department of Industrial Management and Technology, University of Piraeus, Greece. He received his PhD degree in Purchasing Management and his Bachelor's degree in Business Administration from the University of Piraeus, Greece. His teaching, research and consulting interests include purchasing, logistics and materials management. His research work has been published in journals such as Omega, European Journal of Marketing, Production and Inventory Management Journal, International Journal of Operations and Production Management, Industrial Marketing Management and Journal of Supply Chain Management. He is a member of the Hellenic Purchasing Institute, of the Institute of Supply Management and of the Economic Chamber of Greece. 